\title{
Simple and effective models to predict the compressive and tensile strength of HPFRC as the steel fiber content and type changes
}

\author{
V. Savino ${ }^{\text {a }}$ L. Lanzoni ${ }^{\text {b,c,* }}$, A.M. Tarantino ${ }^{\mathrm{c}}$, M. Viviani $^{\mathrm{a}}$ \\ a HEIG-VD - Haute Ecole d'Ingénierie et de Gestion du Canton de Vaud, Route de Cheseaux 1, CH-1401 Yverdon-les-Bains, Switzerland \\ ${ }^{b}$ DESD - Dipartimento di Economia, Scienze e Diritto, University of San Marino, Salita alla Rocca 44, 47890 San Marino, San Marino

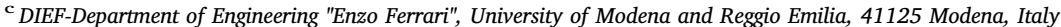

\section{A R T I C L E I N F O}

\section{Keywords:}

Metal-matrix composites

Mechanical properties

Numerical analysis

Mechanical testing

\begin{abstract}
A B S T R A C T
HPFRC/UHPC are today widely applied as repair and reinforcement materials for structures. One of the drawback of commercial HPFRC/UHPC is that any modification of the matrix-fibers mix design, due to the market requirements, affects the mechanical properties of the hardened concrete and therefore the data obtained testing the previous version of the concrete are useless. Prediction models that link the properties of both fibers and matrix to the performances of the hardened concrete are of great practical interest. This paper present a simple and effective model to account for the effect of fibers on the compressive and tensile strengths of HPFRCs as the aspect ratio and volume of fibers changes, extending the range of application of the few existing models.
\end{abstract}

\section{Introduction}

Use of fibers to enhance the mechanical behaviour of brittle materials is not a new concept. Since ancient times straw was used to reinforce sunbaked bricks, as well as horsehairs were used in masonry mortar and plaster to enhance certain mechanical properties. In 1898 the invention of the Hatschek process promoted the commercial use of asbestos fibers in a cement matrix. Between 1960 and 1970 new fiber types were introduced and substituted the asbestos fibers. In the 1960s some researchers investigated the use of steel fibers reinforcement and demonstrated the advantages of this new technology $[35,36]$. With the advent of High- and Ultra High- Performance Fiber Reinforced Concrete (HPFRC/UHPFRC) the steel fibers become popular $[9,15,38,39,51-54,58]$. Concretes are characterized by a low tensile strength and ductility that can be improved by adding steel fibers into the matrix. Steel fibers currently used in cementitious composite materials have much evolved in the past years, thanks to a great number of researches $[6,18,21,28,31,33,34,37,42,49]$, focusing both on the use of innovative steels and on new shapes of the fibers. ${ }^{1}$ These new fibers further improved many engineering properties of HPFRC/UHPFRC $[1,2,17,20,29]$ e.g. tensile strength, compressive strength, elastic modulus, crack resistance and toughness. ${ }^{2}$ Also splitting and crushing resistance of concrete can be enhanced by using steel fibers $[8] .^{3}$

Steel fibers are usually classified by:

- Geometry: several shapes are proposed by the producers e.g. straight, hooked, undulated, flat-end etc;

- Equivalent diameter: for fibers that are not circular in cross-section, the equivalent diameter is the diameter of the circle having the same area of the average cross-section of the actual fiber. The greater the equivalent diameter, the greater the flexural strength;

- Aspect ratio: is a measure of the slenderness of the fiber defined as the ratio between the length of the fiber and the equivalent diameter $\left(l / d_{e}\right)$;

- Volume fraction: is the concentration of fibers within a given unit volume of composite material $\left(V_{f}\right)$;

- Strength: is the stress capacity that fiber reaches before failure;

- Toughness: is considered as the ability of the fiber to adsorb strain energy before failure.

The performances of a HPFRC are influenced by all the abovementioned parameters and by the type and strength of the concrete

\footnotetext{
* Corresponding author. DESD - Dipartimento di Economia, Scienze e Diritto, University of San Marino, Salita alla Rocca 44, 47890 San Marino, San Marino.

E-mail address: luca.lanzoni@unimo.it (L. Lanzoni).

${ }^{1}$ FRC based on synthetic fibers has been investigated, as an example, in Refs. [22,30], whereas a recent study about the retrofitting of concrete beams strengthened by a polymer-based mortar has been addressed in Ref. [23]. The mechanical performances steel cords and a geopolymeric matrix as strengthening system has been discussed in Ref. [3].

${ }^{2}$ Fracture can be modelled, in a nonlinear framework, following Ref. [46], whereas recent contributes about damage mechanics can be found in Refs. [24-26]. Bifurcation and stability in the context of homogeneous finite deformations can be found in Ref. [47].

${ }^{3}$ An interesting study about the fibre/matrix interface in a concrete reinforced with steel fibers can be found in Ref. [41]. Experimental studies about the beneficial aspects of steel fibers in enhancing ductility of RC columns [14] and the punching shear behaviour of slabs [4] have been investigated also.
} 
Table 1

Sampling parameter.

\begin{tabular}{|c|c|c|c|c|c|c|c|c|c|}
\hline $\begin{array}{l}\text { Code } \\
(-)\end{array}$ & $\begin{array}{l}\text { Cube Sample } \\
\text { (n.) }\end{array}$ & $\begin{array}{l}\text { Dog-bone Sample } \\
\text { (n.) }\end{array}$ & $\begin{array}{l}\text { Dosage fiber } \\
(\%)\end{array}$ & $\begin{array}{l}\text { Length } \\
\text { (mm) }\end{array}$ & $\begin{array}{l}\text { Diameter } \\
(\mathrm{mm})\end{array}$ & $\begin{array}{l}\text { Aspect Ratio } \\
(-)\end{array}$ & $\begin{array}{l}\text { Density } \\
(\mathrm{kg} / \mathrm{mc})\end{array}$ & $\begin{array}{l}\text { Weigth } \\
(\mathrm{kg})\end{array}$ & $\begin{array}{l}\text { Tensile Strength } \\
(\mathrm{MPa})\end{array}$ \\
\hline Control & 9 & 9 & - & - & - & - & - & - & - \\
\hline SF65 & 15 & 15 & $1.5,2,3,4,5$ & 20 & 0.3 & 65 & 7850 & $1.11 \times 10^{-5}$ & 1200 \\
\hline SF75 & 15 & 15 & $1.5,2,3,4,5$ & 13 & 0.175 & 75 & 7850 & $2.45 \times 10^{-6}$ & 1250 \\
\hline HF45 & 15 & 15 & $1.5,2,3,4,5$ & 35 & 0.75 & 45 & 7880 & $1.12 \times 10^{-4}$ & 1200 \\
\hline HF65 & 15 & 15 & $1.5,2,3,4,5$ & 35 & 0.55 & 65 & 7860 & $6.54 \times 10^{-5}$ & 1200 \\
\hline HF85 & 15 & 15 & $1.5,2,3,4,5$ & 30 & 0.35 & 85 & 7850 & $2.27 \times 10^{-5}$ & 1000 \\
\hline
\end{tabular}

matrix. Researchers have shown that the aggregates and the steel fibers have been largely influencing both the compressive and the tensile strengths of concrete (e.g. [32,45,50]). Literature contains a wide number of test campaigns on the mechanical properties of HPFRC and UHPFRC but few systematic studies on the effect of the fiber volume and shape on the direct tensile strength have been performed. Furthermore the preferred method to study the effect of fibers on a HPFRC/ UHPFRC are splitting or bending tests that are further correlated with the ductility and other engineering properties. While many models are available for a specific dataset, few researchers attempted to construct a model that predict either the tensile, splitting or bending strength by taking into account the volume fraction of the fibers, the shape of the fibers and the matrix characteristics $([32,45,50]$ et al.). When qualifying a new HPFRC/UHPFRC for a particular field/use, the norms impose large test campaign to define the ductility and the tensile strength of the concrete ([56,62-64]). If to this compulsory testing campaign have to be added a series of test to understand which volume and shape of fiber has to be used to meet the minimum designers' requirement, then the cost of qualification might deter the use of these high technology concretes.

\section{Materials and methods}

For this study twenty-five series of steel fibers with varying shape, aspect ratio $\left(l / d_{e}\right)$ and dosage $\left(V_{f}\right)$ were used to study the compressive and tensile strengths of a marked HPC. The toughness behaviour has also been taken into account. Straight fibers with two different $l / d_{e}$ ratios of 65,75 and hooked-end fibers with three different $l / d_{e}$ ratios of 45, 65 and 85 were used. For each fiber five different $V_{f}$ were taken in account: $1.5 \%, 2 \%, 3 \%, 4 \%$ and $5 \%$. The tensile strength of fibers ranges between 1000 and $1250 \mathrm{MPa}$. Further details are illustrated in Table 1 and Fig. 1.

The exact composition of the commercial HPC investigated in this campaign was unknown since the producer does not provide the mix design (which is simply labeled "premix") and the nature of the compounds. Premixes of HPFRCs usually contain cement, sands and pozzolans. Table 2 shows the compounds to fabricate one cubic meter of the investigated HPFRC according the producer's prescription.

Although fiber addiction does not modify remarkably the yield stress of the fresh mixture, they increase the viscosity. ${ }^{4}$ A good distribution of the steel fibers in the HPC was obtained by using a high intensity rotating pan mixer. During filling the molds a visual examination on flow test of the fresh mixture allowed to detect the formation of fiber clusters. The samples were cast in standard conditions according to [63]. Dimensions of cubes and dog-bone samples, illustrated in Fig. 2, were defined according to[61] and [56], respectively. Once in the molds, concrete composite mixtures were compacted by using a vibrating table and cured according to [60].

In saturated-surface-dry conditions, the measure of density of cubes and dog-bones samples, before testing, allowed to determine whether the shape and dimension of the molds could influence the fiber

\footnotetext{
${ }^{4}$ The mechanical interaction in time between the hosting structure and the cementitiuous reinforcemet is addressed in Refs. [10-12].
}

distribution and quantity in the matrix.

A compression machine Perrier type $138-5000 \mathrm{kN}$ was used to test the compressive strength of the cubes samples according to [61]. A W + B type LVF- $200 \mathrm{kN}$ machine was used to test the direct tensile strength on dog-bone samples according to [56]. The tensile tests were carried out by controlling the axial elongation rate of the specimen that was monitored by a high precision strain gauge. The strain rate was set at $0.05 \pm 0.01 \mathrm{~mm} / \mathrm{min}$. The average real time stress-elongation diagram was recorded for all tensile tests. The end sides of the dog-bone sample were larger than the central part, to allow the clamps of the machine to hold the specimen during the test and to ensure that the failure occurred in the zone monitored by the gauge (Fig. 3).

Each series of the experimental program was composed by three cubes and three dog-bones samples of HPC reinforced with a fixed $V_{f}$ of steel fibers characterized by a given $l / d_{e}$ ratio and shape. For example, the specimens of the first series contain $1.5 \%$ of straight fibers with $l / d_{e}$ ratio of 65 . Each series was labeled according to shape, $l / d_{e}$ ratio and $V_{f}$. SF and HF stand for Straight Fibers and Hooked Fibers; 65, 75, 85, etc. represents the $l / d_{e}$ ratio; $1.5,2,3,4,5$ stand for the $V_{f}$. Moreover, a series of plain concrete samples (nine cubes and nine dog-bones) was used as control (Table 1).

\section{Results and discussions}

\subsection{Fiber distribution and orientation}

During filling the molds it was observed the presence of fiber clusters in the fresh mixture for series HF65_5 and HF85_5. Thus a good distribution of fibers was not obtained and the performances of the hardened HPFRC would be compromised. Therefore the samples of series HF65_5 and HF85_5 were discarded from the investigation. Instead, in series SF75_5, SF65_5 and HF45_5 no fiber clusters were detected. This observation highlighted the impact of the $l / d_{e}$ ratio on the distribution of fibers in the fresh mixture which may play a key role as the $V_{f}$ increases.

Not surprisingly, steel fibers raised the specific weight of all tested concrete. It is interesting to note that the average density of dog-bone series (D) was slightly lower than cube series (C) as can be observed in Fig. 4. The $4 \%$ lower specific weight is probably due to the effect of the complex geometry of the dog-bone molds (wall effect [27]) and the filling capacity of a viscous material such as HPFRC. The orientation effects and the variability of specific weight are well-known issues, such that some standards propose to cut the dog-bones specimens from large slabs of the appropriate thickness ([56] et al.).

An isotropic and homogenous distribution of fiber is also generally assumed in HPFRCs. Nevertheless, the mixing, placing and vibration procedures could affect isotropy. Vibration is not strictly necessary when large quantities of HPFRC are cast, but it is advised to increase the regularity of small specimens. Several researchers $[13,44]$ have investigated the effect of the compaction by vibration on the orientation and segregation of fibers. Most of these investigations showed that external vibration might produce planes of preferentially oriented fibers and likely their segregation. Furthermore the torque forces exerted on the fresh concrete when is flowed are generated by shear stresses 


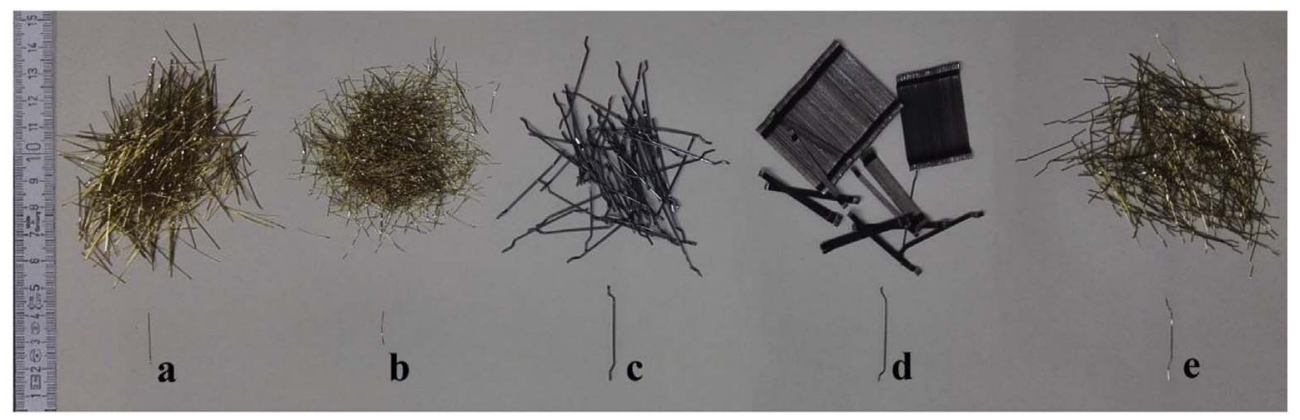

Fig. 1. Types of steel fibers: a) SF65, b) SF75, c) HF45, d) HF65, and e) HF85.

Table 2

Mix design of HPC.

\begin{tabular}{ll}
\hline Mix design of plain concrete & $\mathrm{kg} / \mathrm{m}^{3}$ \\
\hline Premix & 2226 \\
Water & 239.5 \\
Water Retention Agent & 22.3 \\
\hline
\end{tabular}
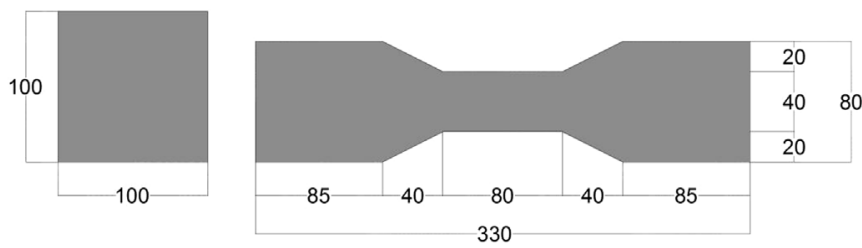

Fig. 2. Sample dimensions: a) cube sample, b) dog-bone sample.

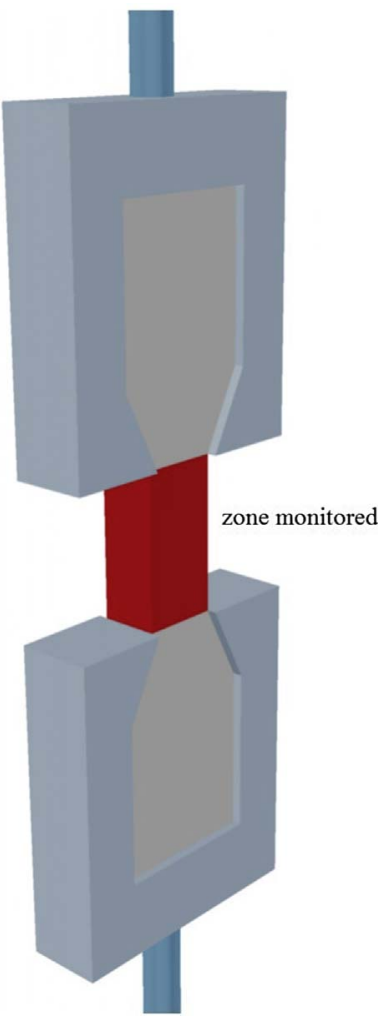

Fig. 3. Zone monitored (in red) on the sample in the direct tensile test. (For interpretation of the references to colour in this figure legend, the reader is referred to the web version of this article.)

and the wall effect, two phenomena that tend to promote preferential orientations. However, in certain cases, the preferential orientation of the fibers is more interesting than isotropic distribution. If the fibers can

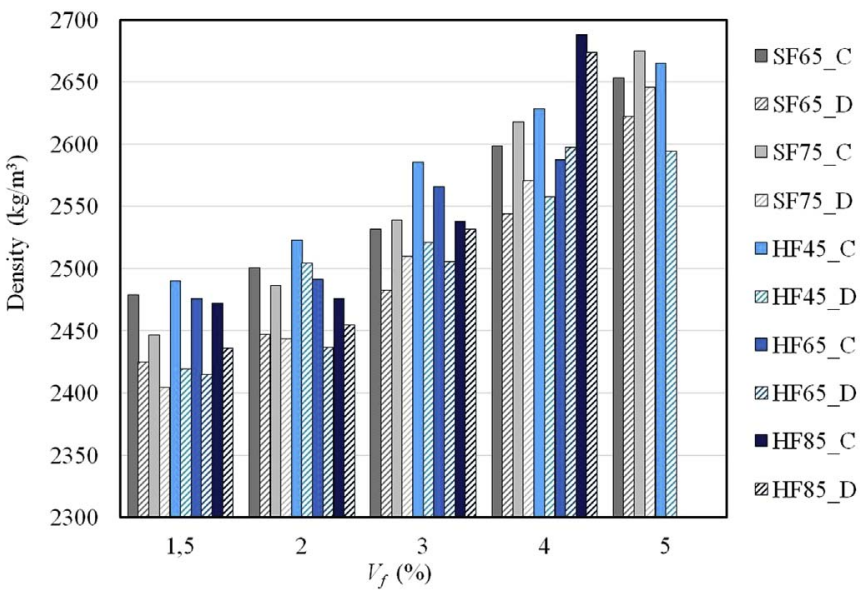

Fig. 4. Comparison of the sample's density.

be oriented perpendicularly to the crack planes, the toughness of the structure will be increased thanks to the higher number of fibers bridging the cracks [40]. The specific weight of each tested type of fibers (SF65, SF75, HF45, HF65 and HF85) is presented in Table 1.

Specimens of series HF45 and HF65 presented a slight fiber segregation. This could be explained considering that even if the shape of these two fibers is similar to the others they are heavier causing the segregation process.

The casting direction on the dog bone specimen tend to promote fibers orientation along the main axis due to shear stresses (arising also by the friction of the concrete with the bottom of the mold) and the wall effect. This phenomenon was virtually unavoidable since the standard dog bones had a cross section of $30 \times 40 \mathrm{~mm}$ and the average length of the studied fibers was of about $30 \mathrm{~mm}$. Consequently is not likely to find a randomly oriented fiber, especially oriented perpendicularly to the main axis. In fact, after testing, all samples were cut in the neighbor the failure section and the orientation was evident (Fig. 5). The cubic molds were filled vertically and the fibers were aligned mainly in horizontal planes, perpendicular to the pouring direction.

\subsection{Compressive strength}

The compressive strength $\left(f_{c}\right)$ values of HPFRC series are given in Table 3. Average compressive strength on cube specimens of the control series $\left(f_{c, \text { matrix }}\right)$ was of about $76 \mathrm{MPa}$. Comparing the values obtained for the control series with HPFRC series was evident a positive effect on the compressive strength, even if this increase was minimal for low $l / d_{e}$ (about $2 \%$ ) and maximum for high $l / d_{e}$ ratios (about 36\%). As $V_{f}$ augmented, $f_{c}$ increased for all series. The small increase of $f_{c}$ in series HF45 was also probably due to the certain degree of segregation of these heavier fibers showing the lowest strength increase. Instead, series HF85 have shown the greatest one, for high $V_{f}$. Considering the presence of fiber clusters in the fresh mixture of series HF65_5 and HF85_5, 4\% of $V_{f}$ seems to be the optimal dosage although the compressive strength increased further until $5 \%$ of $V_{f}$ in the other series, as seen in Fig. 6. 


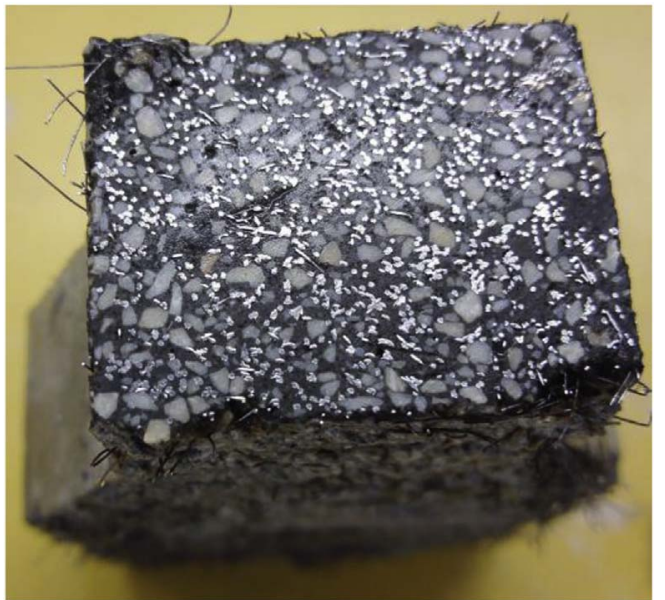

Fig. 5. Distribution and orientation of steel fibers in a HPFRC dog-bone sample.

\subsection{Direct tensile strength}

From direct tensile tests of each series of HPFRC three different parameters were measured or derived: tensile strength $\left(f_{t}\right)$, residual tensile strength $\left(f_{r t}\right)$ and Strain Energy Density (SED). $f_{t}$ was defined as the tensile tension value at the time of the first crack formation in the axial strain range of 0.01 and $0.25 \%$. $f_{r t}$ was the tension value corresponding to the $2 \%$ of axial strain; SED represented the area of the experimental stress-strain under graph, as illustrated in Fig. 7. The mean strength value, calculated in each HPFRC series and in the control series, depended on a population of three and nine samples, respectively. $f_{t}$ value of the control series was 3.3 MPa. For series SF65, SF75, HF45, HF65, HF85 the maximum and minimum $f_{t}$ values were 7.54, $6.24,6.87,6.26,7.34$ and $3.73,4.17,3.41,3.74,4.03 \mathrm{MPa}$, respectively. The relative strengths are presented in Fig. 8 and show an increase of tensile strength in the range $3-128 \%$ compared to the value of the control series $\left(f_{t, \text { matrix }}\right)$. For all HF series, $f_{t}$ increased with increasing $l / d_{e}$ ratio and $V_{f}$. The increase of $f_{t}$ in SF series reached the peak at $4 \%$

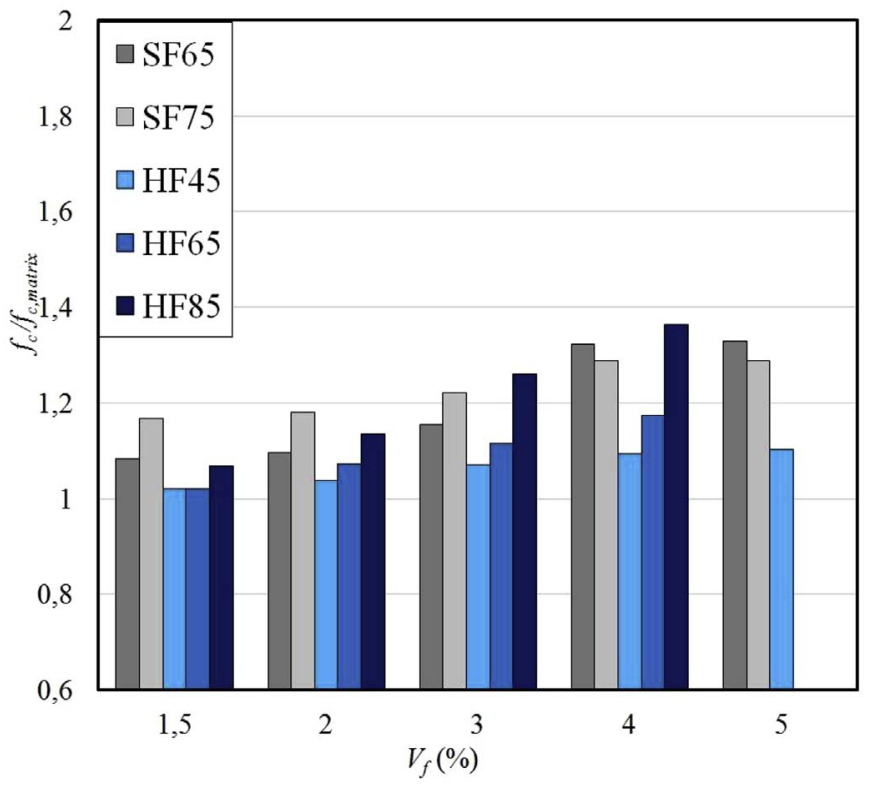

Fig. 6. Effect of $l / d_{e}$ ratio and $V_{f}$ on $f_{c}$.

of $V_{f}$, after which the value decreased. In series SF65_5 and SF75_5, fibers were too close to develop an efficient bridging effect in the cracking section and a drop of strength occurred. In series HF45 and HF65, a slight increase of strength from $1.5 \%$ to $3 \%$ of $V_{f}$ was observed. Even though in series HF45 and HF65 some segregation occurred, for higher $V_{f}(>3 \%)$, the distribution of the fibers in the mixture remained good and good values of strength were obtained. A better increase of tensile strength was observed in series HF85 exhibiting the benefit of fibers with high $l / d_{e}$ ratios.

A softening behaviour after cracking and a not negligible residual strength beyond the $2 \%$ of axial strain was observed. Residual tensile strength $\left(f_{r t}\right)$ values of each HPFRC series are drawn in Table 3. For series SF65, SF75, HF45, HF65, HF85 the maximum and minimum $f_{r t}$

Table 3

Results.

\begin{tabular}{|c|c|c|c|c|c|c|c|c|c|c|c|}
\hline \multirow[t]{2}{*}{ Sample } & \multicolumn{3}{|l|}{$f_{c}$} & \multicolumn{3}{|l|}{$f_{t}$} & \multicolumn{3}{|l|}{$f_{r t}$} & \multicolumn{2}{|l|}{ SED } \\
\hline & $\begin{array}{l}\text { Aver. } \\
(\mathrm{MPa})\end{array}$ & $\begin{array}{l}\text { COV } \\
(\%)\end{array}$ & $\begin{array}{l}\text { Rel. } \\
(\%)\end{array}$ & $\begin{array}{l}\text { Aver. } \\
(\mathrm{MPa})\end{array}$ & $\begin{array}{l}\text { COV } \\
(\%)\end{array}$ & $\begin{array}{l}\text { Rel. } \\
(\%)\end{array}$ & $\begin{array}{l}\text { Aver. } \\
\text { (MPa) }\end{array}$ & $\begin{array}{l}\text { COV } \\
(\%)\end{array}$ & $\begin{array}{l}\text { Rel. } \\
(\%)\end{array}$ & $\begin{array}{l}\text { Aver. } \\
\text { (Mpa) }\end{array}$ & $\begin{array}{l}\text { COV } \\
(\%)\end{array}$ \\
\hline Control & 75.85 & 9.63 & 100.00 & 3.30 & 9.58 & 100.00 & 0.00 & - & 0.00 & 0.02 & - \\
\hline SF65_1.5 & 82.17 & 8.57 & 108.33 & 3.73 & 11.27 & 113.03 & 2.41 & 8.70 & 73.03 & 6.99 & 4.48 \\
\hline SF65_2 & 83.11 & 5.84 & 109.57 & 5.67 & 12.48 & 172.82 & 2.86 & 24.20 & 86.67 & 7.75 & 27.75 \\
\hline SF65_3 & 87.53 & 2.48 & 115.40 & 6.53 & 7.51 & 197.55 & 2.26 & 23.94 & 68.48 & 7.37 & 14.68 \\
\hline SF65_4 & 100.26 & 1.57 & 132.18 & 7.54 & 14.36 & 228.30 & 1.91 & 25.26 & 58.18 & 7.38 & 13.10 \\
\hline SF65_5 & 100.85 & 1.06 & 133.62 & 4.57 & 22.41 & 137.64 & 1.85 & 16.43 & 56.06 & 6.31 & 12.07 \\
\hline SF75_1.5 & 88.56 & 1.26 & 116.76 & 4.17 & 4.79 & 126.3 & 1.47 & 35.49 & 45.24 & 3.78 & 4.63 \\
\hline SF75_2 & 89.50 & 2.46 & 118.00 & 4.28 & 1.93 & 129.70 & 1.13 & 54.03 & 34.30 & 3.80 & 17.30 \\
\hline SF75_3 & 92.71 & 2.55 & 122.51 & 5.10 & 23.95 & 154.55 & 0.90 & 23.91 & 27.27 & 5.86 & 34.51 \\
\hline SF75_4 & 97.65 & 2.66 & 128.74 & 6.24 & 6.30 & 189.09 & 0.83 & 26.99 & 25.15 & 4.06 & 4.71 \\
\hline SF75_5 & 97.74 & 3.05 & 128.86 & 5.91 & 12.20 & 179.09 & 0.67 & 23.13 & 20.17 & 5.36 & 23.56 \\
\hline HF45_1.5 & 77.47 & 1.07 & 102.14 & 3.41 & 5.03 & 103.33 & 1.33 & 22.09 & 40.30 & 3.07 & 24.36 \\
\hline HF45_2 & 78.79 & 5.01 & 103.88 & 3.63 & 6.41 & 110.00 & 1.42 & 38.26 & 43.03 & 4.49 & 10.17 \\
\hline HF45_3 & 81.25 & 2.19 & 107.12 & 3.77 & 14.36 & 114.24 & 1.52 & 6.21 & 46.06 & 5.49 & 29.09 \\
\hline HF45_4 & 83.06 & 2.48 & 109.51 & 4.23 & 29.11 & 128.18 & 1.65 & 23.06 & 50.30 & 5.76 & 6.69 \\
\hline HF45_5 & 83.70 & 2.96 & 110.35 & 6.87 & 11.73 & 208.18 & 1.80 & 10.27 & 54.55 & 8.41 & 5.66 \\
\hline HF65_1.5 & 77.52 & 5.67 & 102.20 & 3.74 & 12.75 & 113.33 & 1.21 & 22.59 & 36.67 & 4.39 & 24.95 \\
\hline HF65_2 & 81.43 & 2.96 & 107.36 & 3.88 & 11.37 & 117.58 & 1.39 & 26.22 & 42.12 & 6.09 & 13.71 \\
\hline HF65_3 & 84.66 & 7.07 & 111.62 & 3.89 & 5.00 & 117.88 & 2.36 & 19.97 & 71.52 & 9.69 & 9.00 \\
\hline HF65_4 & 89.06 & 7.73 & 117.42 & 6.26 & 41.48 & 190.21 & 2.48 & 1.41 & 75.15 & 9.97 & 6.87 \\
\hline HF85_1.5 & 81.03 & 6.41 & 106.83 & 4.03 & 5.44 & 122.12 & 1.46 & 41.37 & 44.03 & 6.48 & 12.94 \\
\hline HF85_2 & 86.15 & 3.07 & 113.58 & 5.43 & 4.47 & 164.55 & 2.75 & 10.05 & 83.33 & 6.79 & 4.21 \\
\hline HF85_3 & 95.60 & 1.78 & 126.42 & 5.69 & 12.26 & 172.42 & 2.90 & 12.85 & 87.88 & 7.47 & 11.65 \\
\hline HF85_4 & 103.52 & 1.44 & 136.42 & 7.34 & 6.34 & 222.42 & 4.17 & 38.88 & 126.36 & 9.05 & 14.20 \\
\hline
\end{tabular}




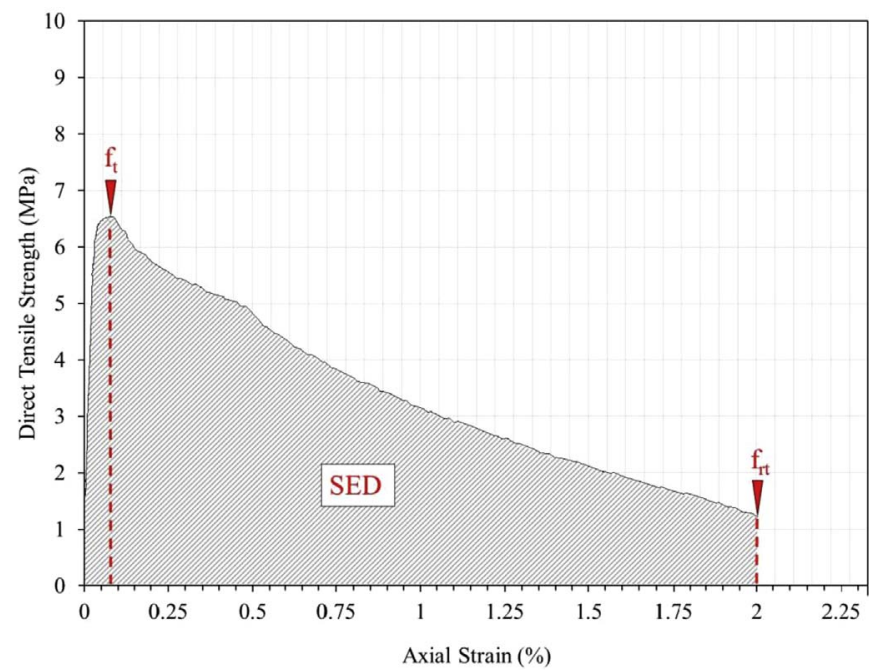

Fig. 7. Parameters of the behaviour of the HPFRC under direct tensile stress.

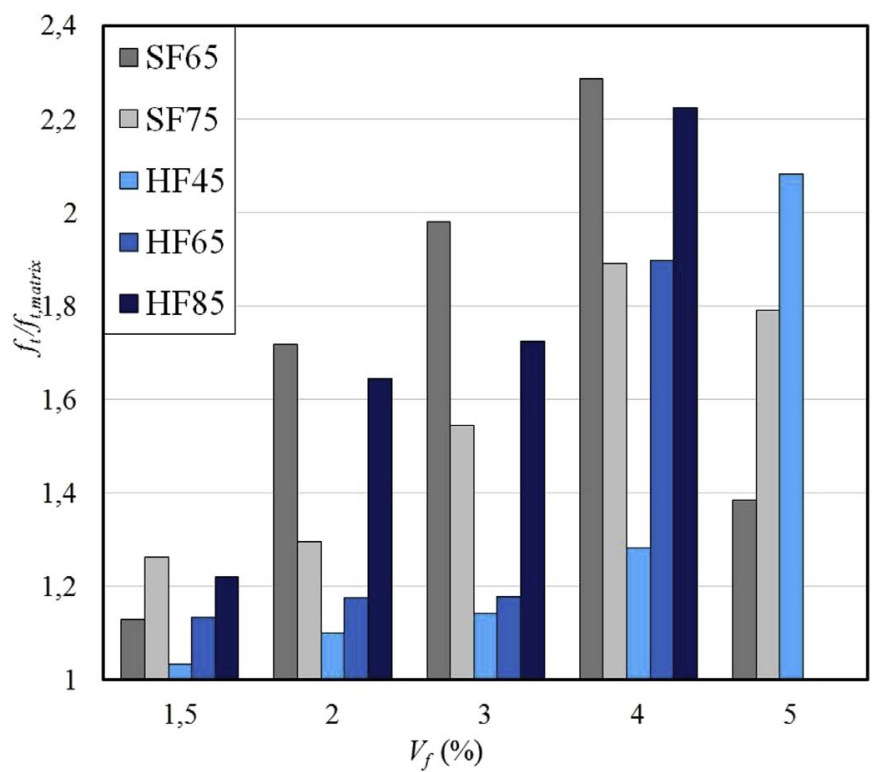

Fig. 8. Effect of $l / d_{e}$ ratio and $V_{f}$ on $f_{t}$.

values were $2.86,1.47,1.8,2.48,4.17$ and $1.85,0.67,1.33,1.21$, $1.46 \mathrm{MPa}$, respectively. The ratio between $f_{r t}$ value of each series and $f_{t, \text { matrix }}$ ranged from 0.2 to 1.26 . It is interesting to note that $f_{r t}$ of a concrete reinforced by SF decreased when $l / d_{e}$ ratio and $V_{f}$ fraction increased. Instead, for concrete reinforced with HF, $f_{r t}$ improved with increasing $l / d_{e}$ ratio and $V_{f}$. In the series HF45, $f_{r t}$ increased slightly augmenting $V_{f}$. More interesting is the behaviour observed in series HF65 and HF85 in which a remarkable increase of $f_{r t}$ was observed with increasing $l / d_{e}$ ratio and $V_{f}$ (Fig. 9). In fact, thanks to both hooked-end shape and high $l / d_{e}$ ratio these fibers enhance the crack bridging process improving the post-cracking behaviour.

The fiber bridging the cracks avoided the brittle failure of the specimens under tensile stresses and improved the toughness. Fig. 10 highlights the influence of $l / d_{e}$ ratio and $V_{f}$ on the toughness via the SED on each series. In series SF65 low dosages of fibers conferred more ductility to the HPFRC than high dosages and a slight reduction of ductility occurred while the amount of fibers increased. Series SF75 showed no obvious improvement of ductility by varying $V_{f}$. Instead HF series clearly denoted that the toughness improved with the increasing of both $l / d_{e}$ ratio and $V_{f}$.

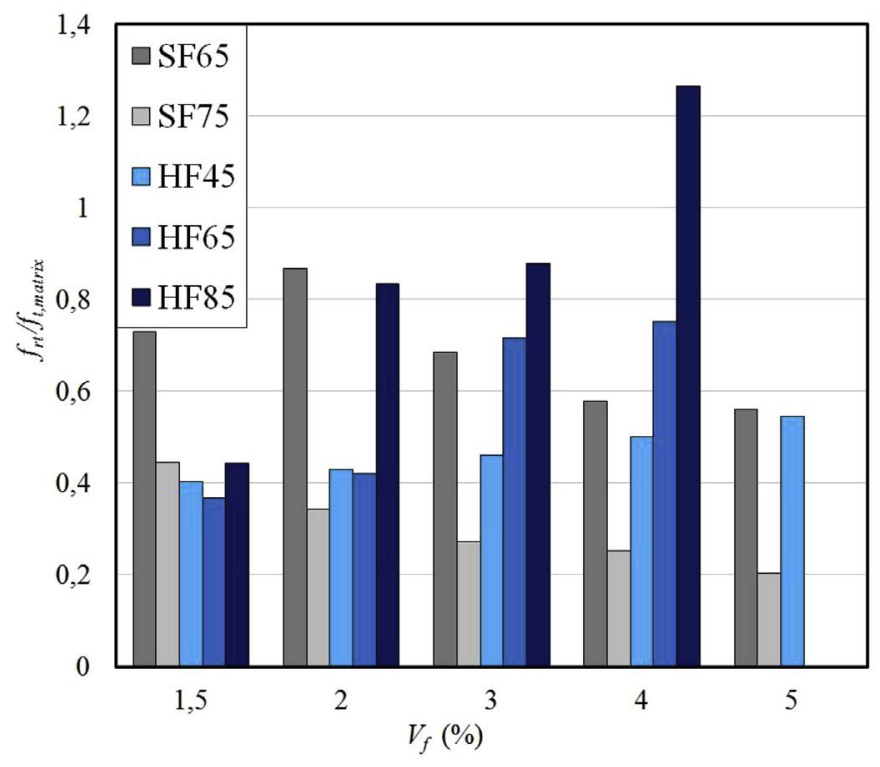

Fig. 9. Effect of $l / d_{e}$ ratio and $V_{f}$ on $f_{r t}$.

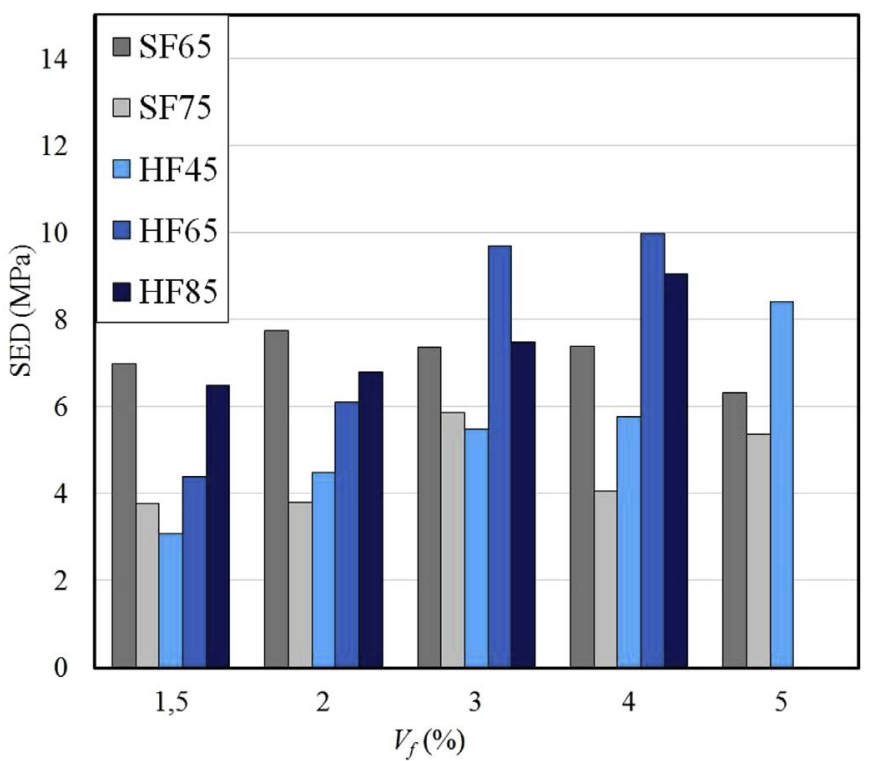

Fig. 10. Effect of $l / d_{e}$ ratio and $V_{f}$ on SED.

Before first cracking occurs the tensile strength was not significantly influenced by the shape of the tested fibers (see Fig. 8). After the matrix crack initiation, the stress is absorbed by the fibers bridging the cracks. The deformation of SF will finally causes the debonding and pull out. Instead, $\mathrm{HF}$ are retained at the hooked ends that plasticize and further crack the surrounding matrix before the fiber is finally pulled out. In fact, $f_{r t}$ value was clearly higher for HPC series reinforced by HF with high $V_{f}$. From a point of view of toughness steel fibers are well-adapted to dissipate strain energy. Even if HF offered the benefit described above the energy-absorbing capability of fibers depend also on both the cross-section of fibers which encounter the crack plane and their elastic properties of the fiber. HF were more efficient in increasing $f_{r t}$. SF conferred to the HPFRC a higher ductility for low $V_{f}$. This effect is probably due to the smaller cross section and higher number of straight fibers bridging the cracks. SF series showed higher values of ductility for $V_{f}$ of 1.5 and $2 \%$, whereas HF series overtook such as values for $V_{f}$ of 3,4 and $5 \%$. 


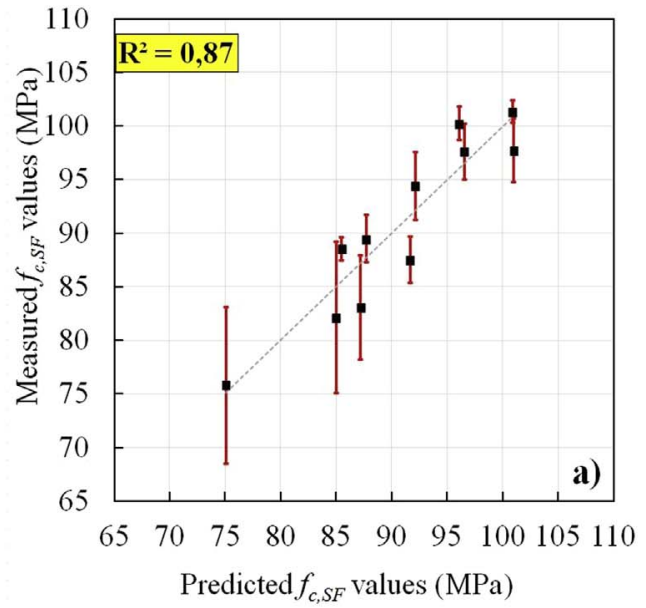

\section{Regression models of compressive and tensile strengths}

\subsection{Predictive models in Literature}

The mechanical behaviour of the HPFRC is affected by the engineer properties of the reinforcing fibers, the concrete matrix and their interactions. For practical purposes is important to know how the tensile and compressive strengths of a HPFRC vary when $l / d_{e}$ ratio, $V_{f}$ and shape of the fibers are changed. Such models, constructed on a specific matrix, permits to know what type and quantity of fibers have to be used in order to meet the designers' requirements.

Several predictive models have been found in Literature. Ramadoss et al. [32] have developed a linear model to predict the compressive and splitting tensile strengths of three mortars reinforced by increasing $V_{f}$ of a single type of steel fibers from 0 to $1.5 \%$. This model is therefore valid if $l / d_{e}$ ratio of the fiber is not changed:

$f_{c f}(\mathrm{MPa})=f_{c}+0.0184 \times R I$

$f_{\text {spf }}(\mathrm{MPa})=f_{\text {sp, matrix }}+0.006 \times R I \quad R^{2}=0.94$

where $R I=w_{f} \times l / d_{e}, w_{f}=$ density of fiber/density of SFRC $\times V_{f}$. Yazıc1 et al. [50] developed a multi-linear relationship between the strengths of a HPC $l / d_{e}$ ratio and $V_{f}$. In this model one matrix was investigated with three types of HF whose $V_{f}$ ranged from 0 to $1.5 \%$ :

$f_{c f}(\mathrm{MPa})=50.4869+0.0434 \times l / d_{e}+1.9667 \times V_{f}(\%) R^{2}=0.10$
$f_{s p f}(\mathrm{MPa})=2.2121+0.0077 \times l / d_{e}+1.4233 \times V_{f}(\%) R^{2}=0.72$.

Sumathi et al. [45] used a second order polynomial equation to regress the relationships between the strengths of a composite concrete and $V_{f}$ of HF while $l / d_{e}$ ratio was kept constant:

$f_{c f}(\mathrm{MPa})=41.45+9.984 \times V_{f}-3.837 \times V_{f}^{2} \quad R^{2}=0.91$

$f_{\text {spf }}(\mathrm{MPa})=3.925+1.448 \times V_{f}-0.042 \times V_{f}^{2} \quad R^{2}=0.99$

where $f_{c}, f_{c f}, f_{s p, \text { matrix }}, f_{s p f}$ and $R I$ are the mean compressive strength of the matrix mortar, mean compressive strength of the fibrous concrete, mean splitting tensile strength of the matrix mortar, mean splitting tensile strength of the fibrous concrete and reinforcing index, respectively.

\subsection{Validation of a general model}

The presented models (see Equations (1)-(6)) were used on the testing campaign described in 2. Finally a new and more general model was developed to predict $f_{c}, f_{t}$ and $f_{r t}$ of HPCs reinforced by steel fibers with different shapes, $l / d_{e}$ ratios and $V_{f}$. Because of the different behaviour between the HPC reinforced with SF and with HF observed in the investigation (see 3) the model is composed of two sub-models, one used for HPCs reinforced by SF (see Equations (7)-(9)) and the other one for HPCs reinforced by HF (see Equations (10)-(12)).

Experimental relationships between SF parameters (such as $l / d_{e}$ ratio and $V_{f}$ ) and $f_{c}, f_{t}$ and $f_{r t}$ have been established by using a multiple linear regression analysis with a confidence of $95 \%$. Since $f_{t}$ decreased with $V_{f}$ exceeding $4 \%$ the linear model of $f_{t}$ does take into account a range of dosage from 0 to $4 \%$. The decrease of $f_{r t}$ as both $l / d_{e}$ ratio and $V_{f}$ increase (see 3.3) is well predicted for $V_{f}$ ranging from 1.5 to $5 \%$.

$f_{c S F}(\mathrm{MPa})=75.1436+0.0499 \times l / d_{e}+4.4016 \times V_{f}(\%) R^{2}=0.84$

$f_{t S F}(\mathrm{MPa})=3.5119-0.0178 \times l / d_{e}+1.876 \times V_{f}(\%) R^{2}=0.78$

$f_{r t S F}(\mathrm{MPa})=11.1266-0.1258 \times l / d_{e}-0.2231 \times V_{f}(\%) \quad R^{2}=0.81$.

When adopting $5 \%$ of $V_{f}$, two out of three tested HF showed a non homogeneous distribution within the fresh mixture (see 3.1), therefore available data for this dosage were not enough to be taken into account in the model. For this reason the behaviour of the concrete reinforced by $\mathrm{HF}$ is well predicted for $V_{f}$ ranging from 0 to $4 \%$, by adopting a linear model.

$f_{\text {cHF }}(\mathrm{MPa})=f_{c, \text { matrix }}+0.0191 \times R I \quad R^{2}=0.80$

$f_{t H F}(\mathrm{MPa})=f_{t, \text { matrix }}+0.0028 \times R I \quad R^{2}=0.72$

$f_{r t H F}(\mathrm{MPa})=0.3166+0.0032 \times R I \quad R^{2}=0.84$.

Figs. 11-13 show the relationships between predicted (see Equations (7)-(12)) and average strength values measured on a population of three samples, for each series. The red bars on each point in the figures represent the deviation standard of the measured strengths. The coefficients of correlation $\left(\mathrm{R}^{2}\right)$ between measured and predicted values are $0.87,0.84,0.95,0.88,0.82$, and 0.84 for $f_{c S F}, f_{t S F}, f_{r t S F}, f_{c H F}, f_{t H F}$ and $f_{r t H F}$, respectively. The high $\mathrm{R}^{2}$ values confirm that the shape, $l / d_{e}$ ratio and $V_{f}$ play an important role in improving the compressive and direct tensile strengths of HPFRCs.

In Figs. 14-16 the models of the author and the experimental results are plotted. It can be immediately observed the different behaviour between the two models in which the HPC is reinforced with SF and HF, especially in terms of post-peak behaviour where $f_{r t}$ of HPC reinforced by SF decreases as $l / d_{e}$ ratio and $V_{f}$ increase, contrary to the case of the HF model (see Fig. 16). This is also the reason why many researchers have concentrated their effort on concretes reinforced by HF (see 4.1).

In Figs. 17 and 18 the new models to predict the compressive and tensile strengths of HPCs reinforced by HF (see Equations (10) and (11)) are plotted and compared with the models found in Literature (see 

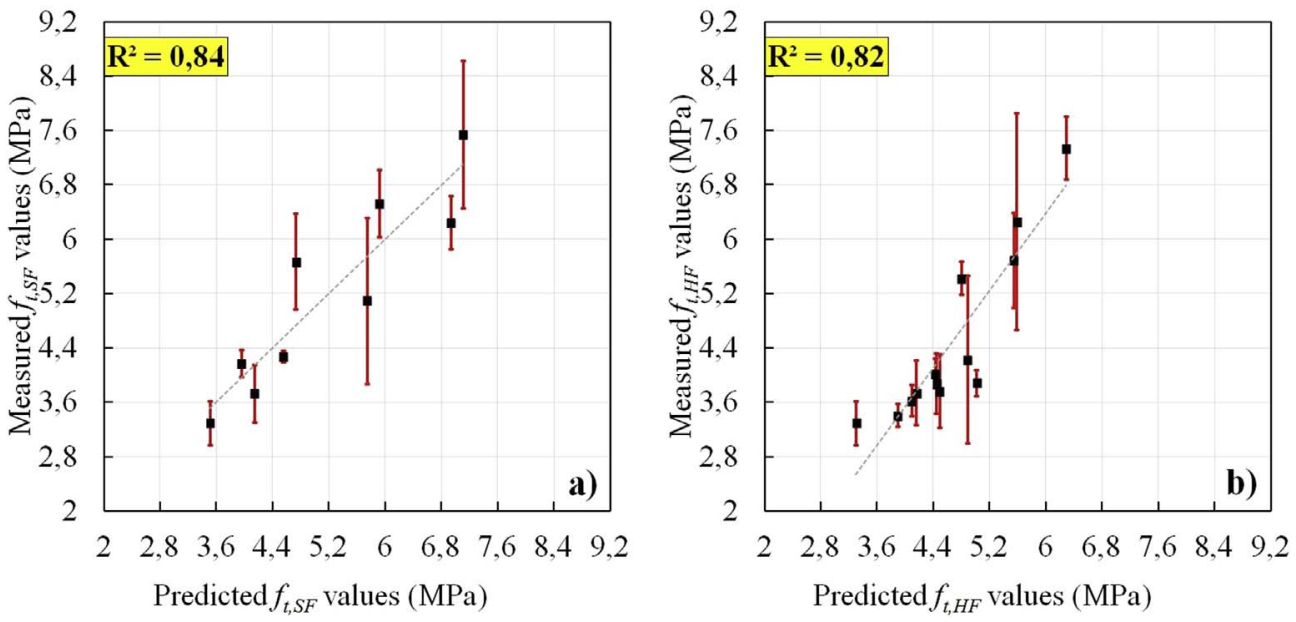

Fig. 12. a) Correlation between predicted and measured $f_{t, S F}$ values, b) Correlation between predicted and measured $f_{t, H F}$ values.
Equations (1)-(6)). The latter have been developed by studying a limited range of $l / d_{e}$ ratios (only one type of fiber has often been studied) and $V_{f}$ (from 0 to 1.5\%). The dotted lines in the Fig. 17 are the range of values obtained extending the prediction of compressive strength listed in Equations (1), (3) and (5), permitting a comparison with the author's models (see Equation (10)) in which three types of fibers ranging from 0 to $4 \%$ were taken into account. It can be observed that all compressive strength models have shown a similar slope confirming that the strength of the HPFRC increases when $l / d_{e}$ ratio and $V_{f}$ increase. [32] have taken into account the compressive strength of the matrix as variable of the model i.e. for a $V_{f}=0 ; f_{c}=f_{c \text {, matrix }}$. The compressive strength of the matrix of the SFRCs investigated in [50] and [45] was not a variable but corresponding approximately to the y-intercept parameter of the model carried out from Equation $(3)(\approx 50 \mathrm{MPa})$ and Equation $(5)$ ( $\approx 40 \mathrm{MPa}$ ), respectively. Substituting the y-intercept value of Equation (3) with the matrix strength value investigated by the author (75.85 MPa) it can be observed that also the model in [50] well agrees with both the model of the author and [32] (Fig. 17). This assumption highlighted that the matrix performances strongly condition the magnitude of the effect of the fibers on the strength of the HPFRC and that similar fibers lead to similar prediction on the strength gain for similar volumes of fibers. The value of the compressive strength of the matrix investigated in this work is also substituted in the model of [45] as the y-intercept parameter in Equation (5). In this case, as shown in Fig. 17, the compressive strength of the SFRC increases until the fiber dosage does not exceed 1.5\%; for higher dosages, the compressive strength decreases. The poor prediction in the model of [45] is likely due to the low strength of the matrix investigated that was not a HPC. In

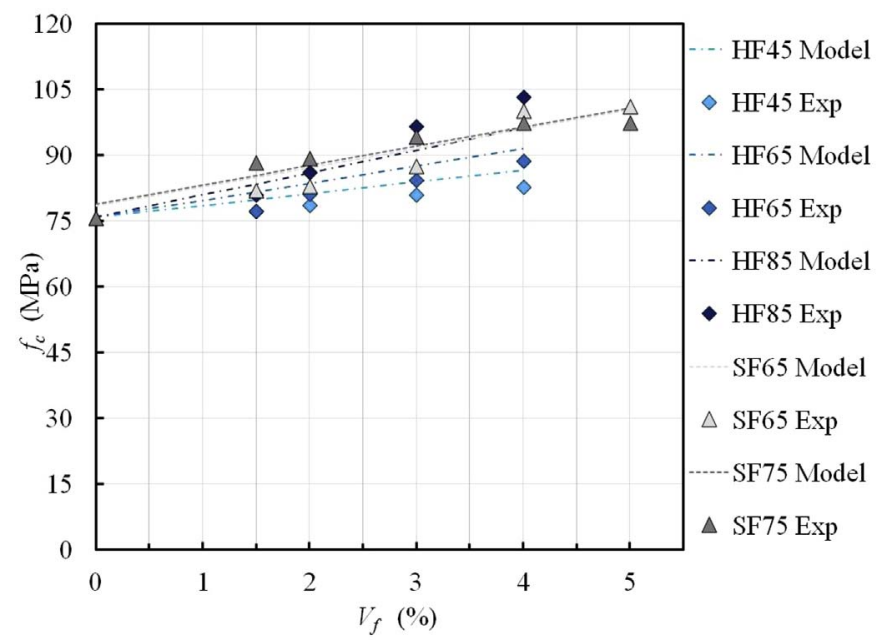

Fig. 14. Models of compressive strength.

fact, within the ordinary concretes the substantial presence of aggregates makes the consolidation of matrix-fiber weaker than in HPCs, leading to a decrease of the strength and toughness of the reinforced concrete as dosage of fiber increases, as seen in [43]. Although the model of the author cannot be used for ordinary concrete it has a good agreement with the models of [32] and [50] for the compressive strength of a HPFRC, if the strength of the matrix is taken into account in the model as variable and if the compressive strength of the matrix is
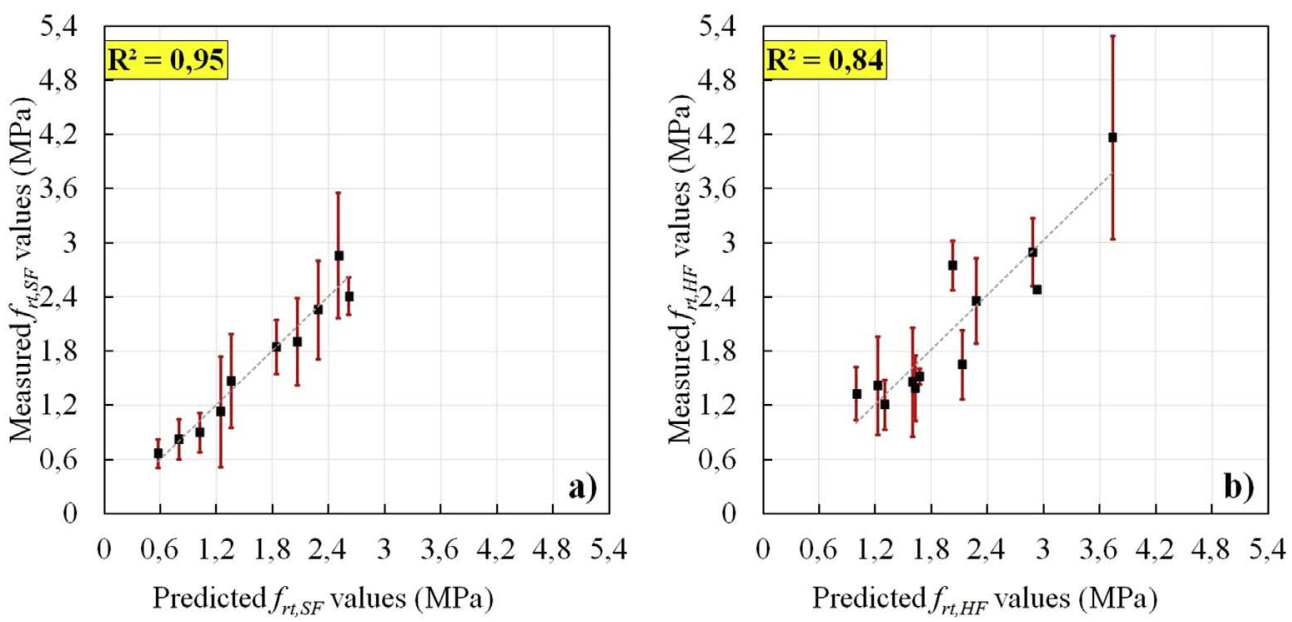

Fig. 13. a) Correlation between predicted and measured $f_{r t, S F}$ values, b) Correlation between predicted and measured $f_{r t, H F}$ values. 


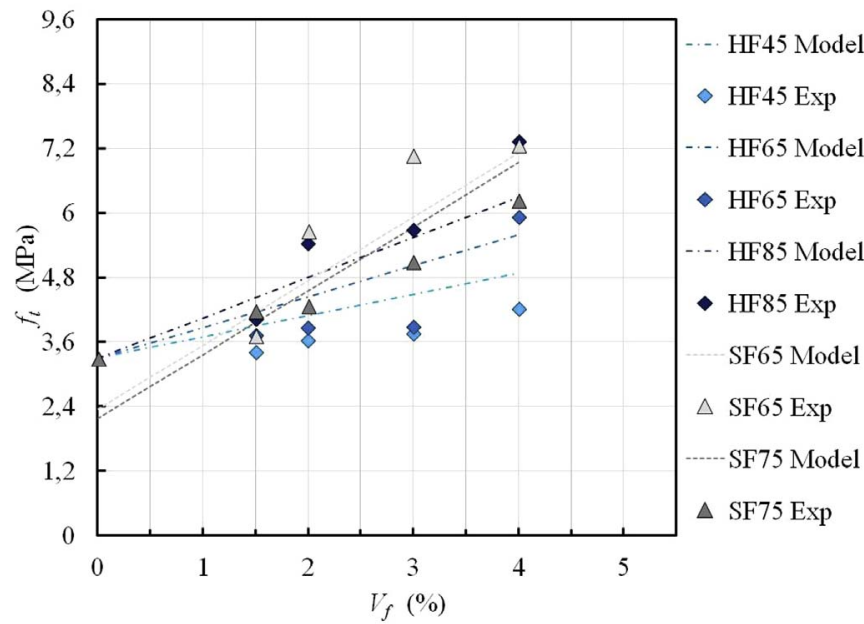

Fig. 15. Models of tensile strength.

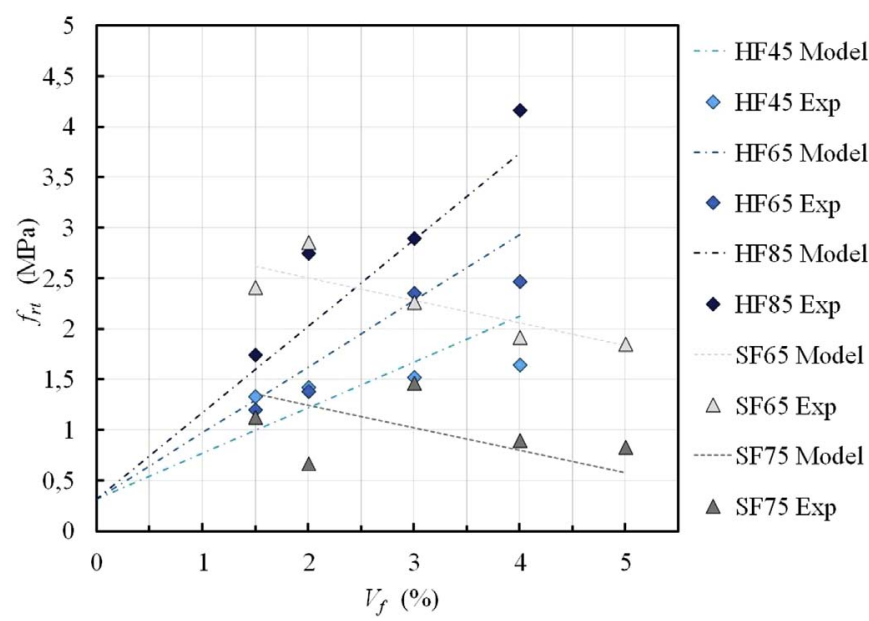

Fig. 16. Models of residual tensile strength.

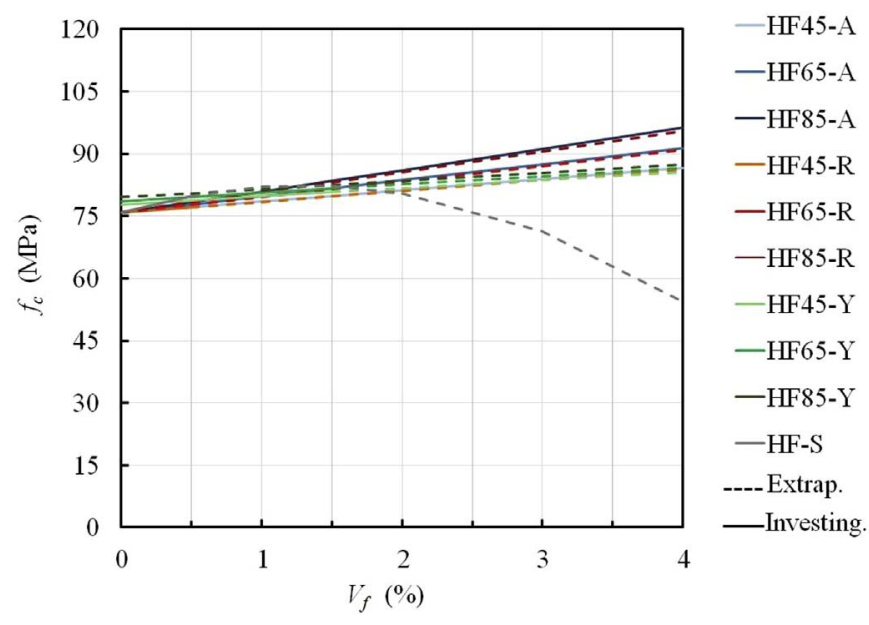

Fig. 17. Comparison between compressive strength models.

higher than $50 \mathrm{MPa}$. The proposed HF model proved to valid up to $V_{f}$ of $4 \%$ and for $l / d_{e}$ ratios ranging from 45 to 85 the prediction of compressive strength of HPFRCs. In Fig. 17, A,R,Y and S stand respectively for: the model of the author, [32], [50] and [45].

Tensile strength can be measured either by indirect methods such as the splitting test (ST) or by direct test (DT). The models found in

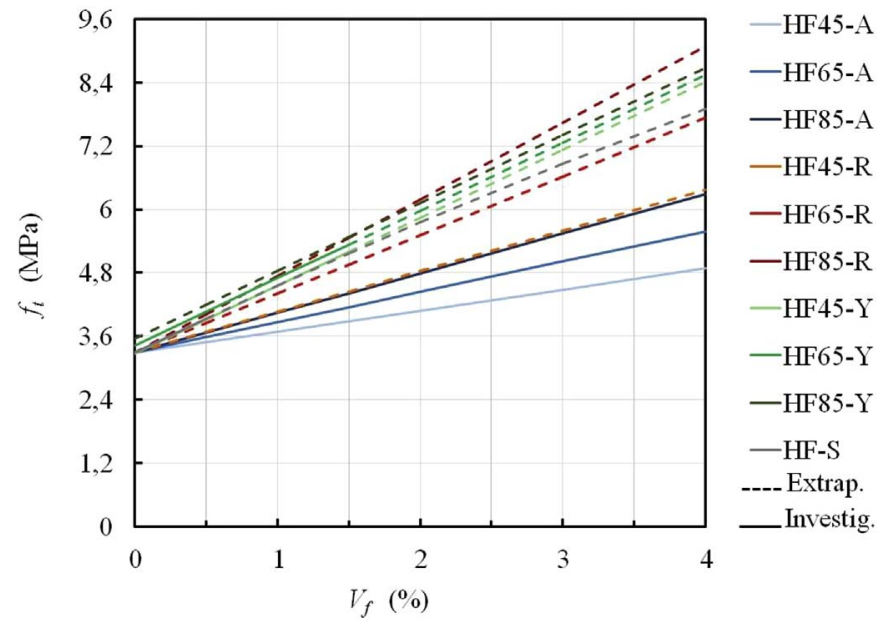

Fig. 18. Comparison between tensile strength models.

Literature to predict the tensile strength have been developed by ST (see Equations (2), (4) and (6)). Although ST is both simple to perform and with low fluctuations of the experimental results, several authors question its applicability for estimating the uniaxial tensile strength (e.g. [5], [16] and [48]). Furthermore the actual codes prescribe DT methods to characterize the physical properties of a HPFRC used in field ([56], [64], [57]). In this work a DT method was used and a tensile model with high $\mathrm{R}^{2}$ values has been obtained (see Equations (7)-(12)). However it can be interesting to compare the authors and the Literature tensile models by using one of the formula given in codes such as [55] that defines the following relationship:

$f_{c t, d t}=0.9 \times f_{c t, s t}$

where $f_{c t, d t}$ is the mean direct tensile strength and $f_{c t, s t}$ is the mean splitting tensile strength. $f_{t, \text { matrix }}$ of the HPC investigated by [32] was a variable of the model (see Equation (2)). In the models of [50] (see Equation (4)), and [45] (see Equation (6)), $f_{t, \text { matrix }}$ values were fix values (4.06 and 4.00 MPa, respectively). Therefore these two models have been modified by using the $f_{t, \text { matrix }}\left(V_{f}=0\right)$ of the HPC investigated by the author (3.3 MPa) converted by using Equation (13). The comparison of models is showed in Fig. 18.

The compressive and the tensile linear models well agree with the Literature and extend the prediction of strength of HPFRCs for $l / d_{e}$ ratios ranging from 45 to 85 and $V_{f}$ ranging from 0 to $4 \%$. Furthermore the tensile model, developed by DT, offers a more realistic prediction with high levels of reliability, in accordance with actual codes and practices.

\section{Conclusions}

An investigation on the influence of steel fiber properties on the compressive strength, tensile strength and toughness of a commercial HPFRC was conducted. As expected the analysis of the results demonstrate that the mechanical behaviour of the tested HPFRC is influenced by the shape of steel fibers, $l / d_{e}$ ratio and $V_{f}$. A new linear mathematical relationships could be established and applied to the new and the Literature dataset. The following conclusions are drawn.

A series of linear relationships between the steel fibers parameters such as $l / d_{e}$ ratio and $V_{f}$ and the performances (compressive and tensile strengths) of a HPFRC could be established. These relationships, established both for HF and SF, extend the range of application of the models found in Literature to determine the optimal $V_{f}$, shape and $l / d_{e}$ ratio of fibers that will allow to meet the designers' requirements in terms of compressive, direct and residual tensile strengths of a given HPFRC. 
The work confirms that a limited number of tests might be appropriate for quality control purposes, thus reducing the overall cost of the HPFRCs.

One of the main variable of all the models is the matrix strength and for ordinary concretes the proposed relationships cannot be used.

The specific weight of the investigated HPFRC increases with using steel fibers until the soil of $300 \mathrm{~kg} / \mathrm{m}^{3}$ is reached.

The compressive and tensile strengths increase between $2-36 \%$ and $3-128 \%$, respectively when fibers are added to the plain HPC. This result shows the efficiency of both SF and HF.

The use of HF influences considerably the toughness of the concrete, when $V_{f}$ increases both in high (85) and low (45) aspect ratio cases an improvement in ductility occurred;

The mixing, casting and vibration procedures influence the distribution, orientation and segregation of fibers. As a consequence, the presence of both slight segregation and fiber clusters were observed in series containing heavy fibers and high dosages, respectively. For these mixes a loss of both strength and toughness at the hardened state occurred.

Finally, this investigation permitted to establish that, if the matrix characteristics of a commercial product are not changed or changes are limited, than a limited testing campaign might be sufficient to predict the behaviour of the new material.

\section{Acknowledgments}

Authors gratefully acknowledge the financial support provided by HEIG-VD. Financial support from the Italian Ministry of Education, University and Research (MIUR) in the framework of the Project PRIN "COAN 5.50.16.01" - code 2015JW9NJT - is gratefully acknowledged.

\section{References}

[1] Ahlborn T.M., Puese E.J., Misson D.L. Ultra-High Performance Concrete for Michigan Bridges. Material Performance-Phase I, MDOT RC-1525CSD-2008-11, pp. 190.

[2] Bastien-Masse M, Brühwiler E. Concrete bridge deck slabs strengthened with UHPFRC. IABSE conference rotterdam assessment, upgrading and refurbishment of infrastructures, vol. 99. 2013. p. 236-7.

[3] Bencardino F, Condello A, Ashour AF. Single-lap shear bond tests on steel reinforced geopolymeric matrix-concrete joints. Compos Part B 2017;110:62-71.

[4] Caratelli A, Imperatore S, Meda A, Rinaldi Z. Punching shear behavior of light weight fiber reinforced concrete slabs. Compos Part B 2016;99:257-65.

[5] Castro-Montero A, Jia Z, Shah SP. Evaluation of damage in brazilian test using holographic interferometry. ACI Mater J 1995;92(3):268-75.

[6] Choi Won-Chang, Jang Seok-Joon, Yun Hyun-Do. Bond and cracking behavior of lap-spliced reinforcing bars embedded in hybrid fiber reinforced strain-hardening cementitious composite (SHCC). Compos Part B 2017;108:35-44.

[8] Conforti A, Tiberti G, Plizzari GA. Splitting and crushing failure in FRC elements subjected to a high concentrated load. Compos Part B 2016;105:82-92.

[9] Daniel JI, Shah SP. Thin-section fiber reinforced concrete and ferrocement SP-124 Detroit: American Concrete Institute; 1990. 441 pp.

[10] Dezi L, Tarantino AM. Time dependent analysis of concrete structures with variable structural system. ACI Mater J 1991;88(3):320-4.

[11] Dezi L, Menditto G, Tarantino AM. Homogeneous structures subjected to successive structural system changes. ASCE J Eng Mech 1990;116(8):1723-32.

[12] Dezi L, Menditto G, Tarantino AM. Viscoelastic heterogeneous structures with variable structural system. ASCE J Eng Mech 1993;119(2):238-50.

[13] Edgington J, Hannant DJ. Steel fibre reinforced concrete. The effect on fibre orientation of compaction by vibration. Mater Struct 1972;5(25):41-4.

[14] Germano F, Tiberti G, Plizzari G. Experimental behavior of SFRC columns under uniaxial and biaxial cyclic loads. Compos Part B 2016;85:76-92.

[15] Gesoglu M, GÃüneyisi E, Muhyaddin GF, Asaad DS. Strain hardening ultra-high performance fiber reinforced cementitious composites: effect of fiber type and concentration. Compos Part B 2016;103:74-83.

[16] Hannant DJ, Buckley KH, Croft J. The effect of aggregate size on the use of the cylinder splitting test as a measure of tensile strength. Mater Struct 1973;6(31):15-21.

[17] Hannawi K, Bian H, Prince-Agbodjan W, Raghavan B. Effect of different types of fibers on the microstructure and the mechanical behavior of Ultra-High Performance Fiber-Reinforced Concretes. Compos Part B 2016;86:215-20.

[18] Jiang L, Niu DT, Bai M. Experiment study on the frost resistance of steel fiber reinforced concrete. Adv Mater Res 2010;243:150-1.

[20] Lackey T, Desgagne G, Benmokrane B, El-Salakawy E, El-Ragaby A. Construction and monitoring of four innovative concrete bridge decks using non-corrosive FRP composite bars. Annu Conf Transp Assoc Can 2004:1-20.

[21] Lane R, Craig B, Babcock W. Materials for blast and penetration resistance. Mater Ease - AMPTIAC Q 2002;6(4).

[22] Lanzoni L, Nobili A, Tarantino AM. Performance evaluation of a polypropylenebased draw-wired fibre for concrete structures. Constr Build Mater 2012;28:798-806.

[23] Lanzoni L, Soragni M, Tarantino AM, Viviani M. Concrete beams stiffened by polymer-based mortar layers: experimental investigation and modeling. Constr Build Mater 2016;105:321-35.

[24] Lanzoni L, Tarantino AM. Damaged hyperelastic membranes. Int J NonLinear Mech 2014;60:9-22.

[25] Lanzoni L, Tarantino AM. Equilibrium configurations and stability of a damaged body under uniaxial tractions. ZAMP Zeitsc. Angew Math Phys 2015;66(1):171-90.

[26] Lanzoni L, Tarantino AM. A simple nonlinear model to simulate the localized necking and neck propagation. Int J NonLinear Mech 2016;84:94-104.

[27] Martinie L, Rouseel N. Simple tools for fiber orientation prediction in industrial practice. Cem Concr Res 2011;41:993-1000.

[28] Moser RD. High-strength stainless steels for corrosion mitigation in prestressed concrete: development and evaluation PhD. Dissertation Atlanta, GA: Georgia Institute of Technology; 2011.

[29] Nazar S, Ismaiel MA, Ahmed M. Possibility to improve strength and structural stability of bridge deck slabs by using ultra high performance fiber reinforced concrete. IOSR J Mech Civ Eng 2014;11:79-87.

[30] Nobili A, Lanzoni L, Tarantino AM. Experimental investigation and monitoring of a polypropylene-based fiber reinforced concrete road pavement. Constr Build Mater 2013;47:888-95.

[31] Popa M, Corbu O, Kiss Z, Zagon R. Achieving mixtures of ultra-high performance concrete. ConstructII 2013;1:40-6.

[32] Ramadoss P, Nagamani K. Tensile strength and durability characteristics of highperformance fiber reinforced concrete. Arabian J Sci Eng 2008;33(2B):307-19.

[33] Ramli M, Dawood E. High-strength flowable mortar reinforced by steel fiber. Slovak J Civ Eng 2011;19(3):10-6.

[34] Rivera-Soto P., Moser R.D., McClelland Z.B., Williams B.A., Williams S.L. Thermal Processing and Alloys Selection To Modify Steel Fiber Performance in Ultra-High Performance Concrete. First International Interactive Symposium on UHPC, 2016.

[35] Romualdi JP, Batson GB. Mechanics of crack arrest in concrete. J Eng Mech Div, ASCE June 1963;89(EM3):147-68.

[36] Romualdi JP, Mandel JA. Tensile strength of concrete affected by uniformly distributed closely spaced short lengths of wire reinforcement. Am Concr Inst K Proc 1964;61(6):657-71.

[37] Sanal I, Ozyurt N, Hosseini A. Characterization of hardened state behavior of self compacting fiber reinforced cementitious composites (SC-FRCC's) with different beam sizes and fiber types. Compos Part B 2016;105:30-45.

[38] Shah SP, Batson GB. Fiber reinforced concrete properties and applications SP-105 Detroit: American Concrete Institute; 1987. 597 pp.

[39] Shah SP, Skarendahl A. Steel fiber concrete. Elsevier Applied Science Publishers, Ltd.; 1986. 520 pp.

[40] Shah, Surendra P, Brandt AM, Ouyang C, Baggot R, Eibl J, et al. High Performance fibre reinforced cement composites Chapter 6 High performance fiber reinforced cement composites 2, vol. 2. 1996.

[41] Simões T, Octávio C, Valença J, Costa H, Dias-da-Costa D, Júlio E. Influence of concrete strength and steel fibre geometry on the fibre/matrix interface. Compos Part B 2017;122:156-64.

[42] Slater E, Moni M, Alam MS. Predicting the shear strength of steel fiber reinforced concrete beams. Constr Build Mater 2012;26:423-36.

[43] Soulioti DV, Barkoula NM, Paipetis A, Matikas TE. Effects of fiber geometry and volume fraction on the flexural behaviour of steel-fibre reinforced concrete. Strain 2011;47:535-41.

[44] Stroeven P. Morphometry of fibre reinforced cementitious materials, Part II: inhomogeneity, segregation and anisometry of partially oriented fibre structures. Mater Struct 1979;12:9-20.

[45] Sumathi A, Saravana Raja Mohan K. Study on the strength and durability characteristics of high strength concrete with steel fibers. Int J ChemTech Res 2015;8(1):241-8.

[46] Tarantino AM. Nonlinear fracture mechanics for an elastic Bell material. Quart J Mech Appl Math 1997;50(3):435-56.

[47] Tarantino AM. Homogeneous equilibrium configurations of a hyperelastic compressible cube under equitriaxial dead-load tractions. J Elast 2008;92:227-54

[48] Tedesco JW, Ross CA, Kuennen ST. Experimental and numerical analysis of high strain rate splitting tensile tests. ACI Mater J 1993;90(2):162-9.

[49] Tjahjanto DD, Suiker ASJ, Turteltaub S, Rivera Diaz del Castillo PEJ, van der Zwaag S. Micromechanical predictions of TRIP steel behavior as a function of micro structural parameters. Comput Mater Sci 2007;41:107-16.

[50] Yazıcı S, İnan G, Tabak V. Effect of aspect ratio and volume fraction of steel fiber on the mechanical properties of SFRC. Constr Build Mater 2007;21. http://dx.doi.org/ 10.1016/j.conbuildmat.2006.05.025. 1250-3.

[51] Yoo DY, Banthia N, Yoon YS. Predicting service deflection of ultra-high-performance fiber reinforced concrete beams reinforced with GFRP bars. Compos Part B 2016;99:381-97.

[52] ACI Committee 544. Revision of state-of-the-Art Report (ACI 544 TR-73) on fiber reinforced concrete. Am Concr Inst J Proc Nov. 1973;70(11):727-44.

[53] ACI Committee 544. State-of-the-Art Report (ACI 544 1R-82(86)) on fiber reinforced concrete. Am Concr Inst J 1982. Detroit, MI, 22 pp.

[54] ACI Committee 506 State-of-the-Art Report (ACI 506 1R-84(89)) on Fiber Reinforced Shot-crete. American Concrete Institute JOURNAL, Detroit, MI, 13 pp.

[55] CEB-FIP MC 90. ComitÃ@ Euro-International du bÃ@ton CEB-FIP Model Code 1990 
1993. $213 / 214$

[56] CNR-DT 204. Guidelines for design, construction and production control of fiber reinforced concrete structures. National Research Council of Italy; 2006.

[57] PrSIA 2052 Béton fibré ultra-performant (BFUP)-Matériaux, dimensionnement et exécution 2015-05.

[58] RILEM Technical Committee 19-FRC. Fibre concrete materials. Mater Struct Test Tes 1977;10(56):103-20.

[60] UNI EN 12390-12392. Testing hardened concrete making and curing specimens for strength tests. 2009.
[61] UNI EN 12390-12393. Testing hardened concrete compressive strength of test specimens. 2003.

[62] UNI 11039-1. Steel fibre reinforced concrete definitions, classification and designation. 2003.

[63] UNI 11039-2. Steel fibre reinforced concrete - test method for determination of first crack strength and ductility indexes. 2003.

[64] UNI 11188. Steel fibres reinforced concrete structural elements design, execution and control. 2007. 